\title{
Análise do Programa "Le Chat 2"\#
}

\author{
M.A. F. A.CAPELA RAMOS* \\ P. AMADOR LOUC $\tilde{A}^{* *}$ I. L', LEAL***
}

\begin{abstract}
O tema, "Equilibrio Químico", faz parte dos conteúdos

programálicos das disciplinas de Físico-Química do $10^{\circ}$ ano e de Química do $12^{\circ} \mathrm{ano}$, além de em outras disciplinas o tema ser suporte de muitos outros assuntos. Por outro lado ao longo de todos estes anos de

experiência temos verificado, que os alunos revelam dificuldades na compreensào de muitos conceitos relativos ao tema, assim como nós professores, tamberm por vezes sentimos dificuldade em ensinar certos fópicos.
\end{abstract}

O programa LeChat (versāu 2.0 ) segue as ubjectivos da virsảo anteriur (verșāo 1.0) [1], em quL sc pretende em particulor visualizar as alleraçōes produxidas em sistctuas químicos gasusus por atlíraçôes de cotrcentraçöes de reagentes ou produtos. cemperatura do sistema vu pressăo (volume) a qué o sistema ustá sujeito cm contormidade com o "Pritucipio de Le Cliatelier".

Tal como a versão ancerior " programa destina-se a alunos do $10^{\prime \prime}$ ' $12^{\prime \prime}$ anos de escolaridade, algumas áreas específicas do curso Tecnológico de Quimica e da disciplina de Técnicas Laboratorais de Quimica yue se relacionem con o tema. Poderào ainda lazer uso do programá os alunos de Química Geral dos primeiros anos universitários.

O programa inicia-se com o aparecimento da ligura de um yato nu visor (trocadilho tentre a palavea gato em francês co nome do grande químico Le Chatclicr e após algums scyundos, entranos directamente no ecrā principal, onde visualizamus várias janelas pelas quais é possivel optar (Fig. I).

Podemos comejar por scleccionar uma das várias eyuaçōes yuímicas disponiveis, ou opur por uma à nossa tscolha. A partir deste momentu cstamos em condiçōes de dar início à simulaçãn clicando na upsāo

no lado esquerdo do ścran. iniciaSe entằn a representaçāo en termos de moléculas e au mussmo tempo să

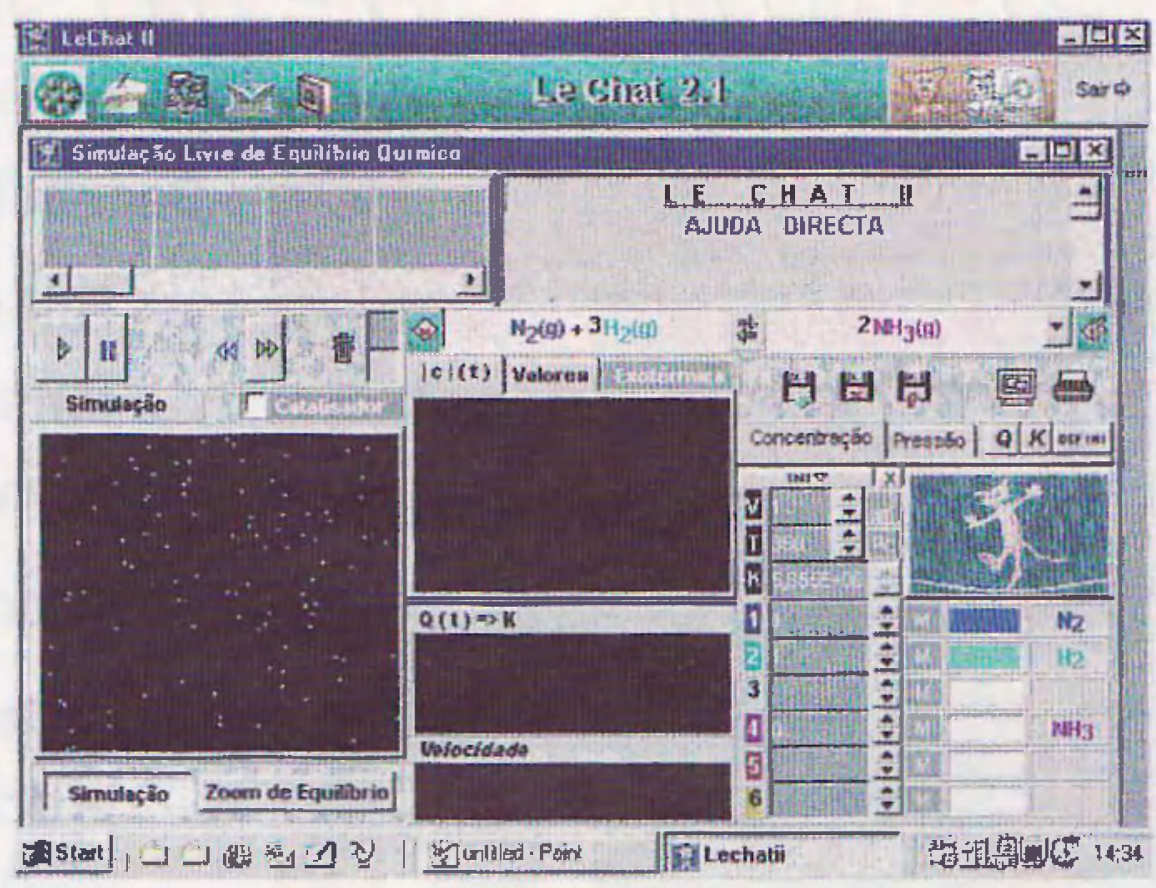

Fig. I - Écran prmatpul to progranta.

traçados gráticos de consentração, de pressão. do yuociltmLL da reacç̃ón : da velocidade l's. u tempo, que sãn visualizados simultaneamerac 17 o écran. Os valores das concentraçōes de reagentes to produlus văo sendo sucessivamence actualizadas en termos numéricos, e em termos de borras culoridas (canto inferior direito). Parece-nos toste aspecio uma boa

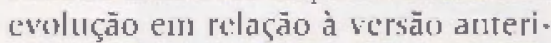
or เัm que năo havia todas estas possibilidades, num eram aprsentadas simultancamcinte. Pedagogicamentu é un aspecto a realçar, แIma vez цис os alunos ao olhartm para u ecrã. poderão ter um parorama geral dc tudo o que se está a passar no vasu de reaccõo e assim compresnder meIhor conctilos, que na maior parto das vezes năo ficam betr apreendidos, como o estado de equilíbrio, a carácter dinâtıicu do equilíbrio. ctc.

Com o programa, tal como na versào anturior, é possivel adicionar utu calalisador c ver o seu cleitu, mas nesta versă este objectivo altugido mais clicazmente uma viz. पuc é possivcl a representaçào gráfica da velocidade, permitindo or uili.
Lador conchic yuc o calatisador não afecta o tseado de coquilibrio, mas apenas a velocidade com que exie é atingido. $\mathrm{O}$ atlizador puderá comparar as representaçỏes grálicas da situaçäo com \& sem calalisador e facilmentc lirar as stuas cunclusōes.

Tatuto na versāı anterior como na prescute é possived alterar as concentraçơes das espécites Intervenicntน's, a temperarura de r'acção. o volume e verificar os sells theitos sobre o sistema em estudo. No entanto, a versăo 2.0 permite seguir passo a passo nāu só a represcentaçào yrálica de Q w. t como latring o seu valor vai solrchdo uma actualizaça stucissiva enu termos numéricos, o gue nos parece vantajoso. O estado de equilíhrio quando atingido assinalado nằ apt"mas pelas setas en cunstante movintento quer tou sentido dircecos conno indirecio, mas também por um sinal sonoro o que constitui um complemento en relaçăo à versāo antcrior. É apresentada ainda a cxpressà do constantu do equilitrio para cada reacgăo, assim como a expressào do respectivo quocientc da

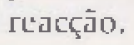


O programa dá-nos lambém па opçăo "Valores" (Figura 1, centro do ccran) valores de $\Delta G^{\circ} . \Delta H^{\square}\left\llcorner\Delta S^{\circ}\right.$ para cadla rcaç̧āo, o que nào acontecia na versäo anterior.

Aprescna lamben na opção "Zoom de Equluibrio" (Figura 1, canto infurior esquerdo) a visualizaçäo microscópica do processu de colisāo molecular, da reacçào do monóxido de carbono com o dióxido de azoto, o que permite relacionta com mais tacilidade o quc acontcce a nivel microscópico conn os cfcitos que se verilicam á cscala macroscópica. Pena ć quc esta representaçăo nicruscópica nảo esıeja disponivel para cada uma das reacçócs cstudadas.

Outra vanlagem que o programa apresconta em relação aे versāo anterior é permitir a listagem dos dados e a respecliva impressão.

Por Fim falıa-mos apenas analisar a barra de ferramentas que se encontra na parte superior do ecrā (Fig. 2).

no clique no primeiro ícone 1emos acesso à "Simulação do Equilíbrio Químico" e abrem-se os ficlieiros simulaçäo live e roleiros (I e 2, Fig. 3).

Ao clicar no item "Editores" (Figura 2) temos acesso a uma biblioteca de dados nunúricos (4. Figura 3) em quc são listados valores de $\Delta_{l} H^{\prime \prime}, \Delta_{1} G^{\circ}$ E. $S^{\circ}$ para diferentes substâncias gasosas; an editor de roteiros (3. Figura 3) em que estão inseridos dois rotciros destinado a alunos do $10^{\text {sano oulro }}$ para os do $12^{\circ}$ ano e por fin um úllíIno destinado a alunos universilários; ao programa de lexto (6. Figura 3 ) onde é possivel o aluno escrever ca à calculadora (13. Figura 3). A possibilidade de colocar alumos em interacçāo usando um Rotciro de Exploracăo é uma das grandes novidades deste programa em relaçăo à versāo anterior. assim como a do programa possuir um Editor de Rotciros que permite aus professores editarem os seus próprios roteiros.

Clicando no terceiro ícone da barra de lerramenias (Figura 2 e 5 . Figura 3) temos acesso ao "Módulo de Intervalo Lúdico", em que o utili7.ador dispōe de várias opçóes lacerlo de equaçōes, substâncias. elementos. adivinlias, charadas ce tabela periódi-

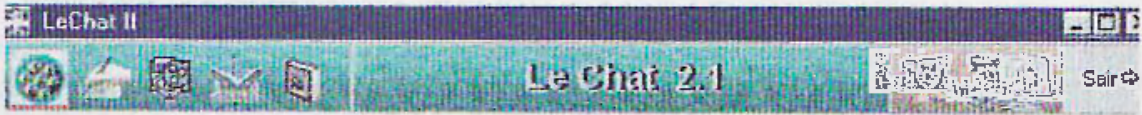

Fig- $z$ - Barra de Fer ramentąn.

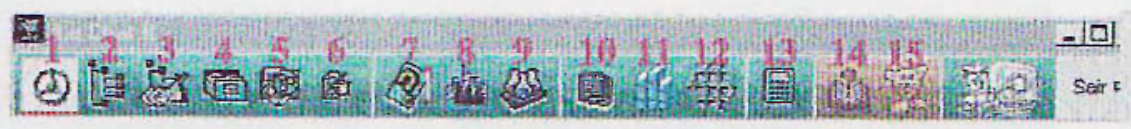

\begin{tabular}{|c|c|c|}
\hline 1 - Simudaçăo Lizre & 6- Editor de Texto & 11 - Eibliograĩa \\
\hline 2 - Roteiros de Explorøçäo & 7. Testes de Muittpla Escolba & 12 - Ligargão à Rede \\
\hline 3-Editor de Roteiros & 8- Equilforio Quimico e Socie dade & If-Calculadora \\
\hline 4 - Dados Numéticos & \multicolumn{2}{|c|}{ '9 - Equilfbrio Quínic o e Laboratória '14 - Hipertextos } \\
\hline 5 - Intertralo Lúdico & 110 - Pressupostos & |15 - Infornaçīo sobre o Proğafna \\
\hline
\end{tabular}

Fig. 1 - Totalidade das opçues disponiveic.

ca), em que poderá clicar e tcrat responder ấs questōes qu: llue vāo sendo propostas. Funciona como um jogo em que sảo atribuidos pontos pelas respostas certas e penalizaçơes pulas crradas. As questôes pockm sc seleccionadas cm três niveis de dificuldade, o que motiva e desafia os jogadores.

Clicando no ícone "Aplicaçós Externas" surgem-nos várias aplicaçōes que nào estão disporíveis na versäo analisada (vcrsão em diskette), mas apenas na versão $3.0 \mathrm{em}$ CD-Rom.

Por fim tho ícone "Inlormaçāa" podcrcmos ter acesso aos Pressuposlos assumidos no programa (10. Figura 3), à Bibliogralia (1 1, Figura 3) disponivel sobre equilibrio quimico. à Ligação à Redc (12, Figura 3) e aos Hipertexios cm Equilíbrio Químico (14. Figura 3) cm gue o aluno ou o prolessor poderá ainda recolher mais informaçōes sobre o tema.

Da análise do programa podemos concluir que o programa "L.e Chat" c um auxiliar riquissimo na inlerpretação e compreensão do terma "Equilibrio Químico", que tem sido referido por muitos prolessores como um tema difícil de ensinar e pelos alunos dificil de aprender. Temos verificado que mujtos dos nossos alumos após terem fetto a aprendizagem do lema, quando o mesmo volta a ser abordado possuem concepcotes trradas, o gue revela dificuldades na aprendizagem. Com o uso deste programa poder-se-á potenciar a compreensão do tema e tacilitar uma correcta aprendizagem dos cunceitos envolvidos.

\section{NOTA FINAL}

Serve a presente nota para chamar a altençäo sobre o artiģo saído no $n^{*} 78$ da Rcvista Química sobre a açẫo Solıciênucia, sobre a disponibilidate deste programa cm rode para quén esteja inreressado cm utilizálo, é para desejar que a Iruluosa experiência do projecto Softciẹncia possa ser retomada num oletro projecto para que possamos continuar a ler softwarc cducativo de qualidade em português.

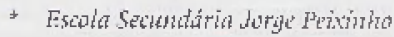

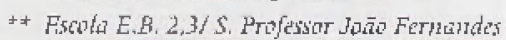
Prians

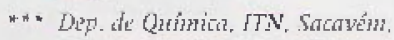

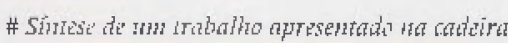

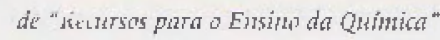

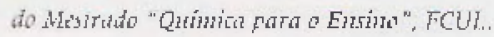

\section{REFERÊNCIA}

I. I. F'. Leal. Quimica 1994, 54, 92. 